\title{
Evaluation of cobalt free coatings as hardfacing material candidates in sodium-cooled fast reactor and effect of oxygen in sodium on the tribological behaviour
}

\author{
Fabien Rouillard ${ }^{1, *}$, Brigitte Duprey ${ }^{1}$, Jean-Louis Courouau $^{1}$, Raphaël Robin ${ }^{1}$, Pascal Aubry ${ }^{2}$, Cécile Blanc $^{2}$, \\ Michel Tabarant ${ }^{2}$, Hicham Maskrot ${ }^{2}$, Laetitia Nicolas ${ }^{3}$, Martine Blat-Yrieix ${ }^{4}$, Gilles Rolland ${ }^{4}$, and Thorsten Marlaud ${ }^{5}$ \\ ${ }^{1}$ Den-Service de la Corrosion et du Comportement des Matériaux dans leur Environnement (SCCME), CEA, \\ Université Paris-Saclay, 91191 Gif-sur-Yvette, France \\ 2 Den-Service d'Etudes Analytiques et de Réactivtiés des Surfaces (SEARS), CEA, Université Paris-Saclay, \\ 91191 Gif-sur-Yvette, France \\ 3 Den-Service de Recherches Métallurgiques Appliquées (SRMA), CEA, Université Paris-Saclay, 91191 Gif-sur-Yvette, France \\ ${ }^{4}$ EDF R\&D, Département Matériaux et Mécanique des Composants, Les Renardières, 77818 Moret Loing Orvanne, France \\ ${ }^{5}$ FRAMATOME, DTIML, 10 rue Juliette Récamier, 69006 Lyon, France
}

Received: 11 February 2019 / Received in final form: 20 May 2019 / Accepted: 2 August 2019

\begin{abstract}
The feedback produced by operating Sodium-cooled Fast Reactors (SFRs) has shown the importance of material tribological properties. Where galling or adhesive wear cannot be allowed, hardfacing alloys, known to be galling-resistant coatings, are usually applied on rubbing surfaces. The most used coating is the cobalt-base alloy named Stellite $6{ }^{\circledR}$ because of its outstanding friction and wear behaviour. Nevertheless, cobalt is an element which activates in the reactor leading to complex management of safety during reactor maintenance and mainly decommissioning. As a consequence, a collaborative work between CEA, EDF and FRAMATOME has been launched for selecting promising cobalt-free hardfacing alloys for the 600 MWe Sodium-cooled Fast breeder reactor project named ASTRID. Several nickel-base alloys have been selected from literature review then deposited by Plasma Transferred Arc or Laser Cladding on $17 \mathrm{Cr}$ austenitic stainless steel $316 \mathrm{~L}(\mathrm{~N})$ according to RCC-MRx Code (AFCEN Code). Among the numerous properties required for qualifying their use as hardfacing alloys in SFR, good corrosion behaviour and good friction and wear behaviour in sodium are essential. First results on these properties are shown in this article. Firstly, the corrosion behaviour of all coatings was evaluated through exposure tests in purified sodium for $5000 \mathrm{~h}$ at $400^{\circ} \mathrm{C}$. All coatings showed an acceptable corrosion behaviour in sodium. Finally, the friction and wear properties of one alloy candidate, NiCrBSi alloy, were studied in sodium in a dedicated designed facility. The influence of the oxygen concentration in sodium on the friction and wear properties was evaluated.
\end{abstract}

\section{Introduction}

Several zones in the Sodium-cooled Fast Reactors (SFRs) are in contact and undergo friction during reactor lifetime. The main examples are the insertion and removal of the assembly feet in their candles during fuel replacement or the movement of control rods into the reactor core during operation. During these operations, excellent friction coefficient and very low wear of the components are necessary. Beyond these properties, it is also necessary that the used materials have good compatibility in sodium, good mechanical behaviour, metallurgical stability, irradiation resistance, etc. Many studies have been carried out since

\footnotetext{
* e-mail: fabien.rouillard@cea.fr
}

the 1950s to determine the best possible pairs of material for all applications. The design of SFR prototypes has led to develop specific installations in order to measure the friction coefficient of pairs of materials and to evaluate wear during friction in sodium. The tribological behaviour of tens pairs of materials was evaluated and reported in literature as function of temperature [1], contact stress, roughness [1,2], sliding rate [1,3], irradiation [4], oxygen content in sodium $[1,5]$ and other parameters. From this "material screening", feedbacks have shown that tribological hard coatings are most of the time necessary in order to limit the wear of the components and prevent them from jamming or blocking. Stellite $6^{\circledR}$, a cobalt-base alloy containing hard phases, has been the most widely used coating in SFRs. Unfortunately, this alloy has the disadvantage of activating into high energy gamma emitter 
Table 1. Weight chemical composition and main phases of the coatings, PTAW = Plasma Transferred Arc Welding and $\mathrm{LC}=$ Laser Cladding.

\begin{tabular}{|c|c|c|c|c|c|c|c|c|}
\hline Hardfacing alloy & Process & Base & $\mathrm{Cr}$ & $\mathrm{C}$ & $\mathrm{Si}$ & $\mathrm{B}$ & Other & Main phases \\
\hline \multirow{3}{*}{$\begin{array}{l}\text { CoCrW } \\
\left(\text { eq. Stellite } 6^{\circledR}\right)\end{array}$} & PTAW & $\mathrm{Co}$ & 28.3 & 1.1 & 1.1 & 0.0025 & $\mathrm{~W}: 4.7$ & $\begin{array}{l}\text { Co-Cr solid solution dendrites }+ \\
\text { interdendritic }\left[\mathrm{Co}+\mathrm{Cr}_{7} \mathrm{C}_{3}\right] \text { eutectic } \\
\text { with primary tungsten and chromium } \\
\text { carbides }\end{array}$ \\
\hline & $\mathrm{LC}$ & Co & 28.1 & 1.2 & 1.3 & / & $\mathrm{W}: 4.8$ & $\begin{array}{l}\text { Co-Cr solid solution dendrites }+ \\
\text { interdendritic }\left[\mathrm{Co}+\mathrm{Cr}_{7} \mathrm{C}_{3}\right] \text { eutectic } \\
\text { with primary tungsten and chromium } \\
\text { carbides }\end{array}$ \\
\hline & PTAW & $\mathrm{Ni}$ & 12.7 & 0.4 & 3.4 & 2.1 & / & $\begin{array}{l}\mathrm{Ni} \text { solid solution dendrites with } \\
\text { binary eutectic }\left[\gamma-\mathrm{Ni}+\mathrm{Ni}_{3} \mathrm{~B}\right] \text { and } \\
\text { chromium borides and carbides }\end{array}$ \\
\hline NiCrBSi A & $\mathrm{LC}$ & $\mathrm{Ni}$ & 12.6 & 0.3 & 3.5 & 2.2 & / & $\begin{array}{l}\mathrm{Ni} \text { solid solution dendrites with } \\
\text { binary eutectic }\left[\gamma-\mathrm{Ni}+\mathrm{Ni}_{3} \mathrm{~B}\right] \text { and } \\
\text { chromium borides and carbides }\end{array}$ \\
\hline \multirow[t]{2}{*}{ NiCrBSi B } & PTAW & $\mathrm{Ni}$ & 12.7 & 0.4 & 3.3 & 1.8 & / & $\begin{array}{l}\text { Ni solid solution dendrites with } \\
\text { binary eutectic }\left[\gamma-\mathrm{Ni}+\mathrm{Ni}_{3} \mathrm{~B}\right] \text { and } \\
\text { chromium borides and carbides }\end{array}$ \\
\hline & PTAW & $\mathrm{Ni}$ & 15.5 & 0.04 & 3.4 & / & Mo: 32.7 & $\begin{array}{l}\text { Ni solid solution }+ \text { Laves Phase Mo- } \\
(\mathrm{Ni}-\mathrm{Cr})-\mathrm{Si}\end{array}$ \\
\hline NiMoCrSi & $\mathrm{LC}$ & $\mathrm{Ni}$ & 16.4 & 0.04 & 3.7 & / & Mo: 32.8 & $\begin{array}{l}\text { Ni solid solution }+ \text { Laves Phase Mo- } \\
\text { (Ni-Cr)-Si }\end{array}$ \\
\hline NiCrSiWB & PTAW & $\mathrm{Ni}$ & 9.6 & 0.7 & 5.0 & 0.5 & $\mathrm{~W}: 1.9$ & $\begin{array}{l}\text { Ni solid solution dendrites with } \\
\text { binary eutectic }\left[\gamma-\mathrm{Ni}+\mathrm{Ni}_{3} \mathrm{Si}\right] \text { and } \\
\text { nickel borides and chromium carbides }\end{array}$ \\
\hline $316 \mathrm{~L}(\mathrm{~N})$ & / & $\mathrm{Fe}$ & 17.4 & 0.03 & 0.32 & / & $\begin{array}{l}\text { Ni: } 12.2 \\
\text { Mo: } 2.6\end{array}$ & $\gamma-\mathrm{Fe}$ \\
\hline
\end{tabular}

${ }^{60} \mathrm{Co}$ hence leading to problems during maintenance and dismantling. As a consequence, research program on several hard nickel-base alloy coatings has been launched through a CEA-EDF-FRAMATOME collaboration. Firstly, their corrosion behaviour in purified sodium at $400^{\circ} \mathrm{C}$ was studied up to $5000 \mathrm{~h}$ of exposure. This temperature corresponded to the operating temperature of the candles positioned at the bottom of the core. Then, in order to study their tribological behaviour in sodium, a low-scale sodium facility dedicated to tribological studies was developed at CEA-Saclay. The results obtained during the friction of $316 \mathrm{~L}(\mathrm{~N})-316 \mathrm{~L}(\mathrm{~N})$ and $316 \mathrm{~L}(\mathrm{~N})-\mathrm{NiCrBSi}$ alloy contacts in sodium at $200^{\circ} \mathrm{C}$ were analyzed. Finally, the effect of oxygen concentration in sodium on the tribological behaviour was evaluated.

\section{Materials and experimental procedure}

\subsection{Sodium preparation}

The corrosion test was carried out into $2.4 \mathrm{~L}$ static sodium bath contained in molybdenum crucible. Molybdenum was used because it has a very low solubility in hightemperature sodium and corrodes very slowly [6]. The Mo crucible was placed in a nickel-base alloy reactor. In order to limit the pollution of sodium by oxygen, all sodium manipulations and the high-temperature corrosion test itself were carried out in a glove box flushed by high-purity argon. After sodium skimming, zirconium getter foil was inserted into the sodium bath then heated to $600{ }^{\circ} \mathrm{C}$ for several days in order to pump out any dissolved oxygen in sodium. With such procedure, the oxygen level in the sodium bath was decreased below $1 \mathrm{ppm}$ in order to be as close as possible to the steady-state oxygen concentration evaluated in former French SFRs' primary sodium $(<3 \mathrm{ppm})$ [7-9]. Once the sodium purification step was done, the nickel-base alloy reactor was opened and the coated specimens were put into the sodium bath with a new zirconium getter foil in order to ensure a very low oxygen concentration in sodium $(<1 \mathrm{ppm})$ at any time of the corrosion test.

\subsection{Samples and analytical techniques}

$2 \mathrm{~mm}$-thick hardfacing alloys were coated on one single face of $316 \mathrm{~L}(\mathrm{~N})$ steel grade specimens $(25 \mathrm{~mm} \times 50 \mathrm{~mm} \times 15 \mathrm{~mm})$ in which our specimens $(25 \mathrm{~mm} \times 20 \mathrm{~mm} \times 3 \mathrm{~mm})$ were machined before exposition into purified liquid sodium at $400{ }^{\circ} \mathrm{C}$ for $500 \mathrm{~h}, 1000 \mathrm{~h}, 3000 \mathrm{~h}$ and $5000 \mathrm{~h}$. The composition of the hardfacing alloy powders, the processes used for making the coatings and the main phases identified in the coatings are given in Table 1 . All coatings were deposited 
a)

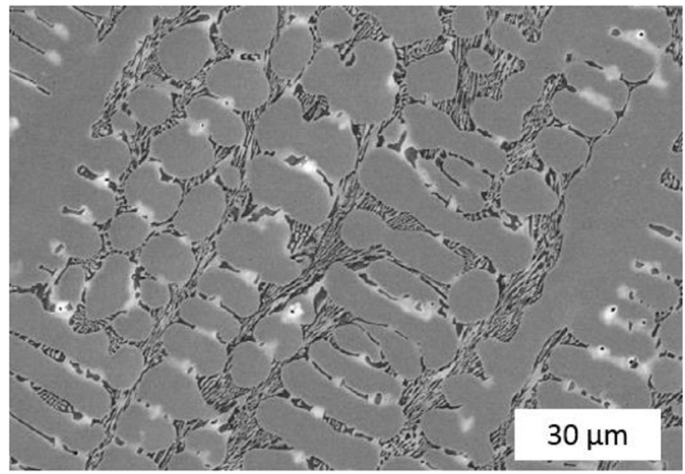

b)

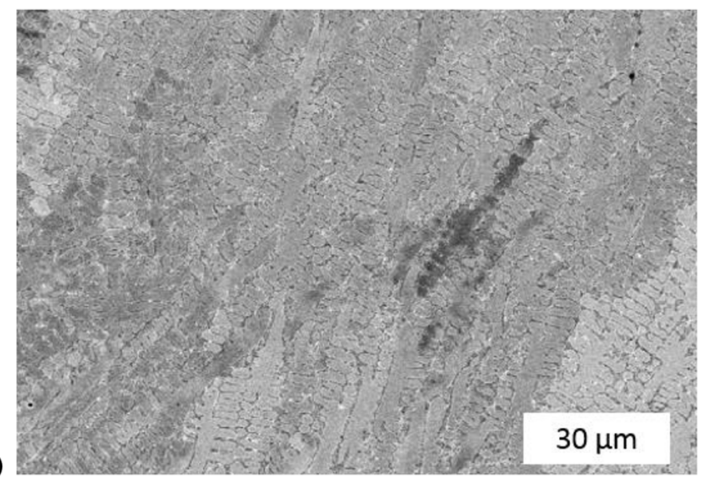

Fig. 1. FESEM images of CoCrW alloy cross-section deposited by (a) PTAW and (b) LC.

a)

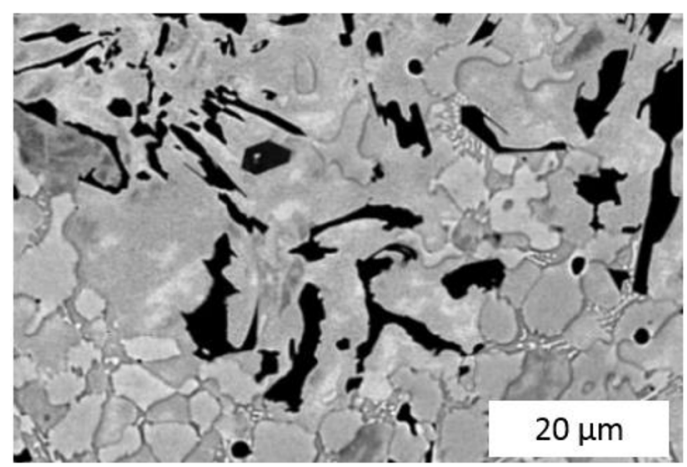

b)

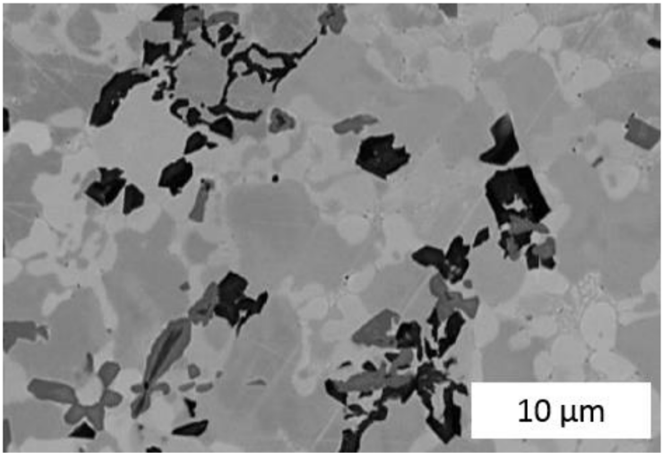

Fig. 2. FESEM images of NiCrBSi A alloy cross-section deposited by (a) PTAW and (b) LC.

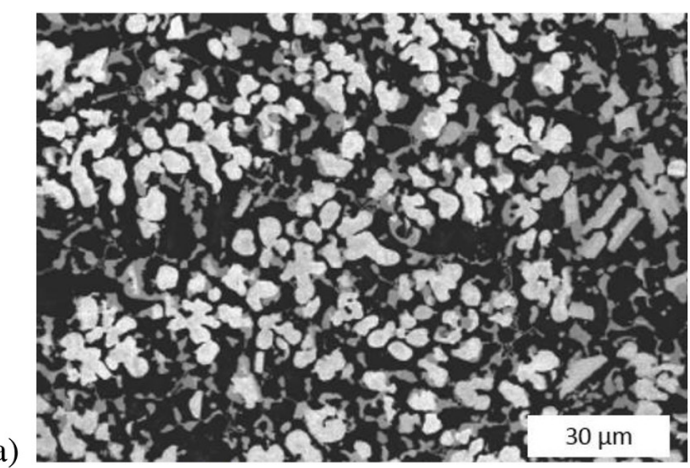

b)

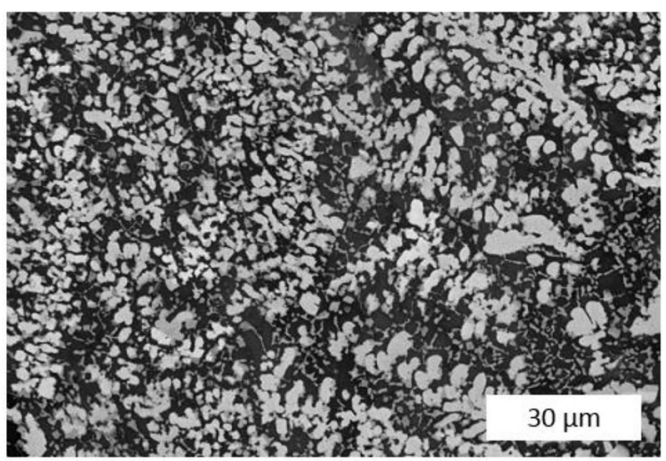

Fig. 3. FESEM image of NiMoCrSi alloy cross-section deposited by (a) PTAW and (b) LC.

by Plasma Transferred Arc Welding (PTAW) in industrial conditions. CoCrW, NiCrBSi A and NiMoCrSi were also deposited on $316 \mathrm{~L}(\mathrm{~N})$ substrate by Laser Cladding (LC) at CEA research lab. The different coating microstructures are strongly linked with the deposited energy used during processing. Coatings with a finer microstructure and a higher hardness could be obtained by the LC process thanks to its very high cooling rate. Hence, the size of the lamellar dendrites $\left(\mathrm{Co}+\mathrm{Cr}_{7} \mathrm{C}_{3}\right)$ formed in the $\mathrm{CoCrW}$ coating was about ten times lower when deposited by LC
(Fig. 1). FESEM images of all the obtained coating cross sections are given in Figures 1-4. More details on the used coating processes and coating metallurgy are given in [10]. The surface of all coatings was grinded before corrosion and friction test. The arithmetic average roughness $R_{\mathrm{a}}$ of the coating surfaces was measured below $0.4 \mu \mathrm{m}$. After immersion, all the coupons were cleaned from sodium residues with the same well-controlled procedure: a first step in pure ethanol, then in water and then again in pure ethanol for $20 \mathrm{~min}$ in an ultrasonic bath. Sample weight 

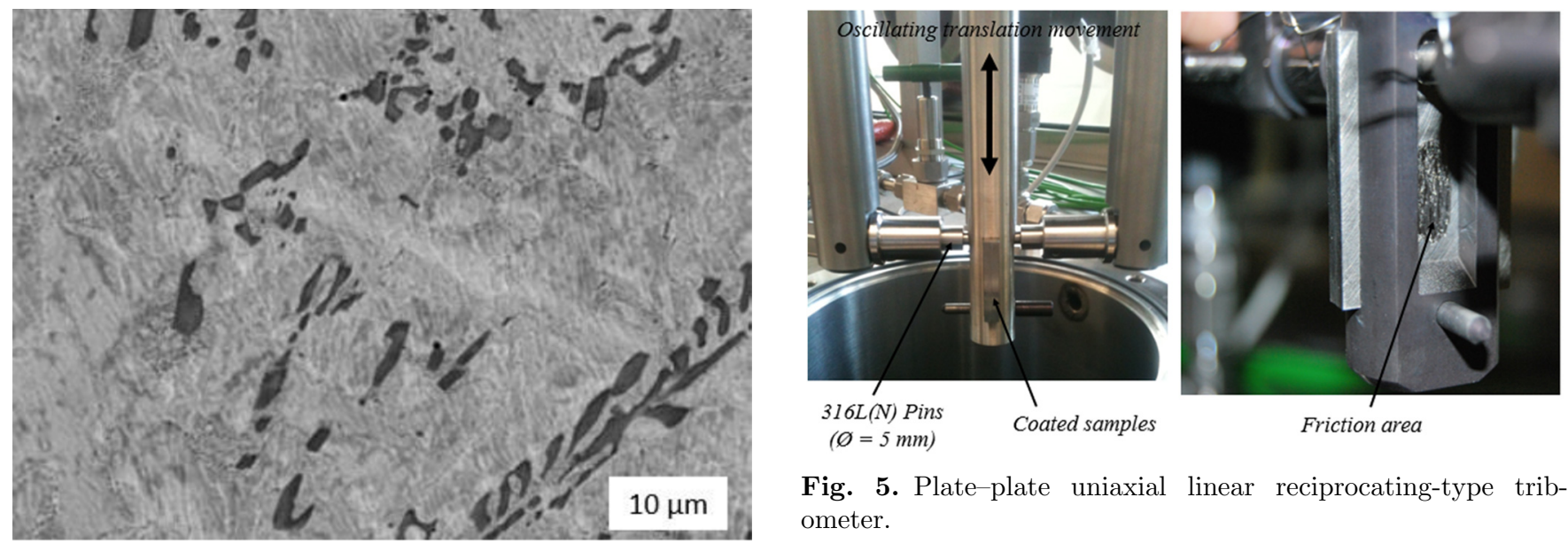

Fig. 5. Plate-plate uniaxial linear reciprocating-type trib-

Fig. 4. FESEM image of NiCrSiW alloy cross-section deposited ometer.

by PTAW.

Table 2. Friction tests.

\begin{tabular}{lllllll}
\hline Central specimens & $\begin{array}{l}\text { Outer } \\
\text { specimens }\end{array}$ & Environment & $\begin{array}{l}\text { Operating } \\
\text { temperature } \\
\left({ }^{\circ} \mathrm{C}\right)\end{array}$ & $\begin{array}{l}\text { Contact } \\
\text { stress } \\
(\mathrm{MPa})\end{array}$ & $\begin{array}{l}\text { Rubbing } \\
\text { speed } \\
(\mathrm{mm} / \mathrm{s})\end{array}$ & $\begin{array}{l}\text { Total rubbing } \\
\text { distance }(\mathrm{m})\end{array}$ \\
\hline $316 \mathrm{~L}(\mathrm{~N})$ & $316 \mathrm{~L}(\mathrm{~N})$ & Argon & 200 & 31 & 1 & 4 \\
$316 \mathrm{~L}(\mathrm{~N})$ & $316 \mathrm{~L}(\mathrm{~N})$ & Purified sodium & 200 & 31 & 1 & 4 \\
NiCrBSi alloy B (PTAW) & $316 \mathrm{~L}(\mathrm{~N})$ & Purified sodium & 200 & 31 & 1 & 4 \\
NiCrBSi alloy B (PTAW) & $316 \mathrm{~L}(\mathrm{~N})$ & Non purified sodium & 200 & 31 & Variable & 4 \\
\hline
\end{tabular}

Purified sodium $=[\mathrm{O}]<1 \mathrm{ppm}$; Non purified sodium $=[\mathrm{O}]>10 \mathrm{ppm}$. The rubbing speed is defined as the speed at which the coated specimen moves relatively to the pin; the total rubbing distance is defined as the total distance travelled by the pin on the coated sample.

variation method was used for evaluating and ranking the corrosion resistance of all samples (mass difference error assessed to be $0.01 \mathrm{mg} / \mathrm{cm}^{2}$ ). Finally, the samples were characterized by optical and Field Emission Scanning Electron Microscopy (FESEM). Modification of the surface composition at the sub-micron scale was carefully followed by Glow Discharge Optical Emission Spectroscopy (GDOES).

\section{Tribological facility and tribological test procedure}

In-sodium friction and wear tests were carried out using a plate-plate uniaxial reciprocating-type tribometer similar to the one presented in $[3,11]$. A photo of the facility is shown in Figure 5 . The two outer pin specimens $(5 \mathrm{~mm}$ in diameter) were made in $316 \mathrm{~L}(\mathrm{~N})$ steel grade for all friction tests and had flat shape. The central specimen was made of two back to back positioned coated or non-coated $316 \mathrm{~L}(\mathrm{~N})$ samples. The two outer $316 \mathrm{~L}(\mathrm{~N})$ pins were pressed against the central specimens by lever arms with the load applied by weights. During the friction test, the central specimen was moved up and down by the central pull rod.
The friction force was recorded by a load cell and the dynamic friction coefficient $\mu$ were calculated by using equation: $\mu=\frac{F_{T}}{2 \times F_{N}}$ with $F_{T}$, the friction force and $F_{N}$, the normal force in Newtons. The normal applied force was accurately calibrated before test, thanks to in situ loadcells positioned in place of the outer specimens. The measurement uncertainty on the applied force given in Table 2 was estimated to be around $10 \%$. Friction tests were carried out on $316 \mathrm{~L}(\mathrm{~N})-316 \mathrm{~L}(\mathrm{~N})$ and $316 \mathrm{~L}(\mathrm{~N})$ $\mathrm{NiCrBSi}$ alloy B (PTAW) contacts. NiCrBSi alloy (whose trade name is Colmonoy $5^{\circledR}$ ) has been identified by recent studies as a promising candidate to replace Stellite $6^{\circledR}$ $[12,13]$. The friction test parameters are detailed in Table 2 . The chosen contact stress and rubbing speed values in the tests were of the same order of magnitude as the values calculated during operation in the reactor. In order to evaluate the influence of the oxygen concentration in sodium on the tribological behaviour of the tested materials, friction tests in purified and non-purified sodium were carried out. For the friction test in purified sodium, the specimens were heated in sodium containing zirconium strip at $600{ }^{\circ} \mathrm{C}$ for 3 days then cooled down at $200^{\circ} \mathrm{C}$ before starting the friction test. This temperature, $200^{\circ} \mathrm{C}$, corresponds to the temperature at which the friction 


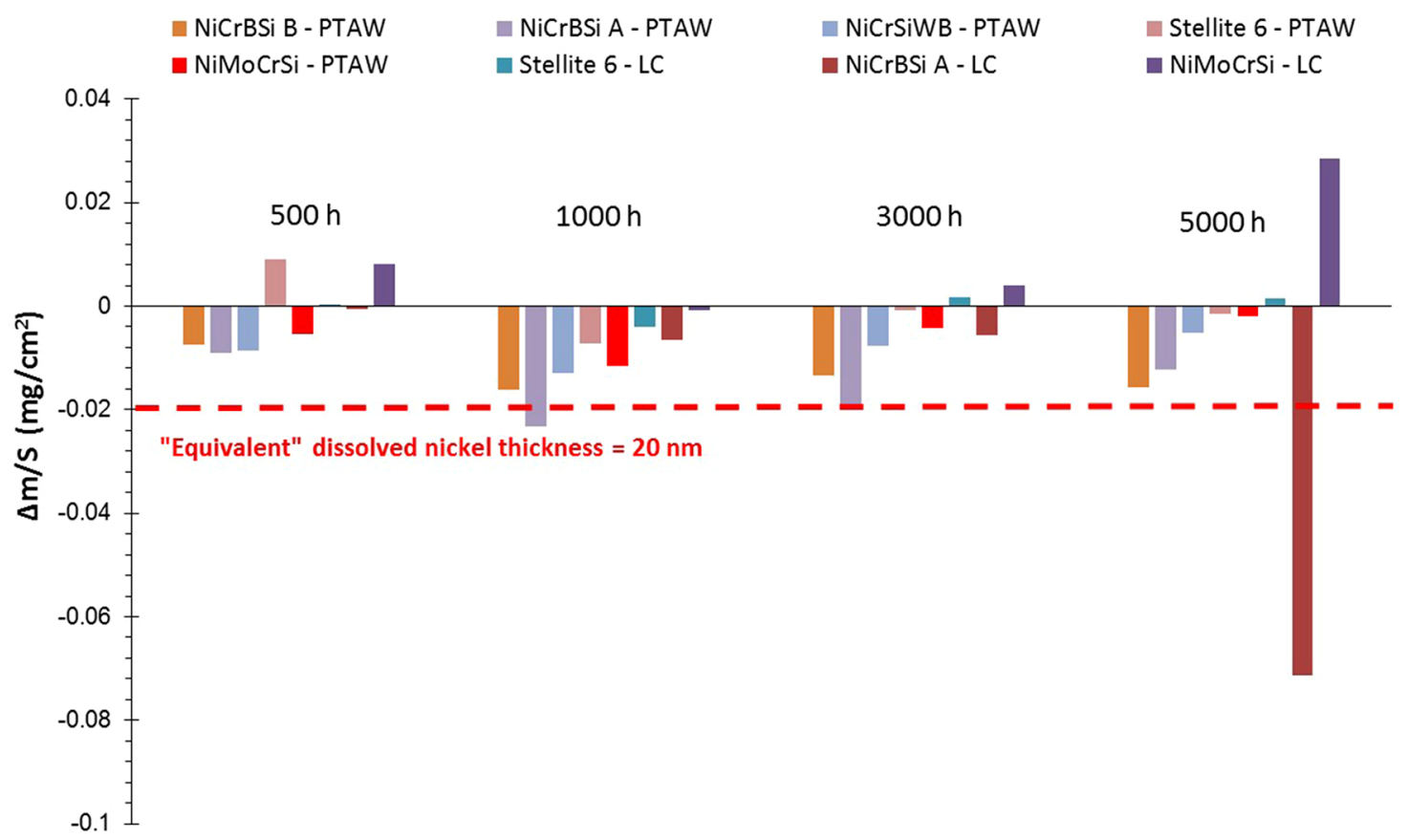

Fig. 6. Mass evolution $\left(m(\mathrm{t})-m_{0}\right)$ of the coated samples after $5000 \mathrm{~h}$ at $400^{\circ} \mathrm{C}$ in purified sodium $-[\mathrm{O}]<1 \mathrm{ppm}$.

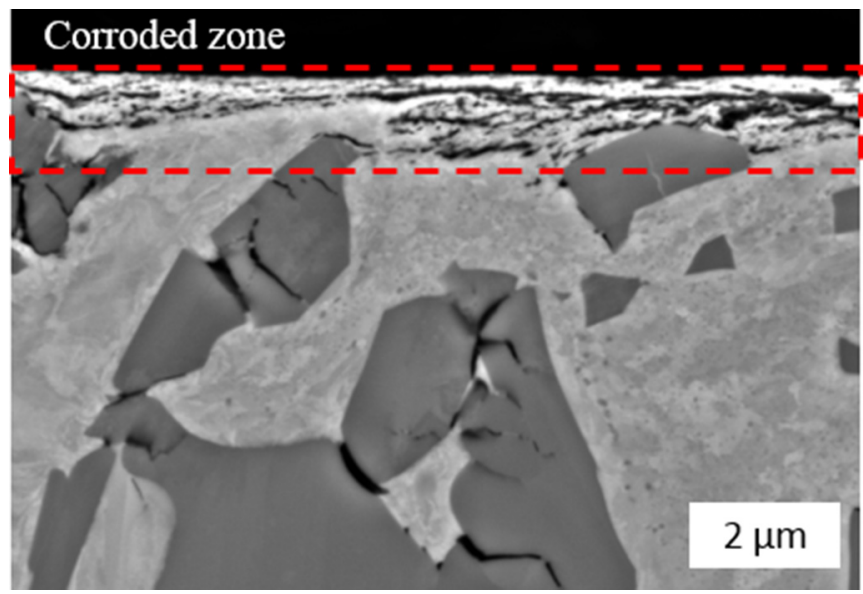

Fig. 7. FESEM image of NiCrBSi alloy A (PTAW) cross-section surface after exposure in sodium at $400^{\circ} \mathrm{C}$ for $5000 \mathrm{~h}$.

movement occurs between the assembly feet and the coated candles during fuel replacement. In this friction test, the oxygen concentration in sodium was estimated below $1 \mathrm{ppm}[5,12,13]$. For the friction test in non-purified sodium, the same procedure was carried out but without any zirconium strip in sodium. The oxygen concentration in the sodium bath in that case was measured between 10 and $20 \mathrm{ppm}$ by sodium post-test purification procedure with zirconium getter foil.

\section{Corrosion results and discussion}

The time evolution of the coated sample weight after exposure at $400^{\circ} \mathrm{C}$ in purified sodium is shown in Figure 6 .
All samples lost weight except $\mathrm{NiMoCrSi}$ and $\mathrm{CoCrW}$ alloys deposited by LC, which gained weight. It must be emphasized that the mass loss or mass gain for all coatings (except NiCrBSi A alloy deposited by LC) were extremely low: after $5000 \mathrm{~h}$ of exposure, the mass loss was lower than an equivalent $20 \mathrm{~nm}$-thick dissolved nickel layer. Any dissolution kinetic determination was not possible given the uncertainties of measurements on weight evolution with time. The very low corrosion rate of the coatings was in good agreement with the low surface alteration observed macroscopically: the samples still appeared metallic coloured with the initial machining traces visible on their surface. The degraded zone at the surface of all coatings was observed by FESEM on cross sections. The larger degraded thickness layer was observed on the NiCrBSi alloy A (PTAW): a $1 \mu \mathrm{m}$ thick porous zone formed at the surface after $5000 \mathrm{~h}$ (Fig. 7). This corrosion feature is in good agreement with the dissolution of the coating into the hot sodium bath.

The modification of the composition of the coatings at the surface was measured accurately with a high depth resolution by GDOES. For all coatings, the composition of these four elements appeared to vary on the surface: B, Cr, $\mathrm{Si}$ and Na. Figures 8-11 show the elementary composition evolution of the surface of NiCrBSi alloy B, CoCrW, $\mathrm{NiCrSiW}$ and NiMoCrSi surfaces deposited by PTAW on $316 \mathrm{~L}(\mathrm{~N})$ steel after exposure at $400^{\circ} \mathrm{C}$ for $5000 \mathrm{~h}$ in sodium. The influence of the process of deposition on the corrosion behaviour is shown for NiCrBSi alloy A in Figures 12 and 13 .

Firstly, boron was depleted on the surface of the boronrich coatings $\mathrm{NiCrBSi}$ alloys $\mathrm{A} / \mathrm{B}$ and $\mathrm{NiCrSiWB}$ alloy whatever the deposition process (PTAW or LC). The depth of boron depletion increased with exposure time. 


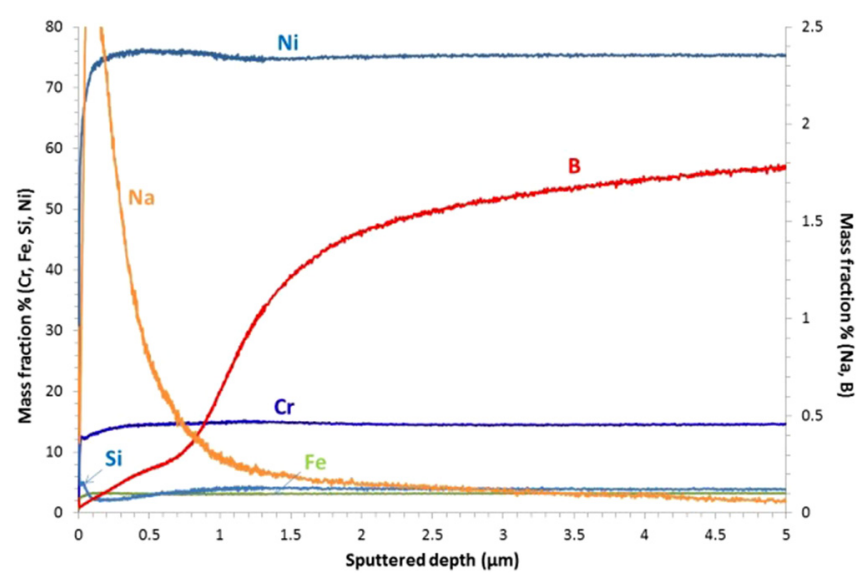

Fig. 8. Elementary profile of NiCrBSi alloy B (PTAW) surface after exposure in $\mathrm{Na}$ at $400{ }^{\circ} \mathrm{C}$ for $5000 \mathrm{~h}$ measured by GDOES.

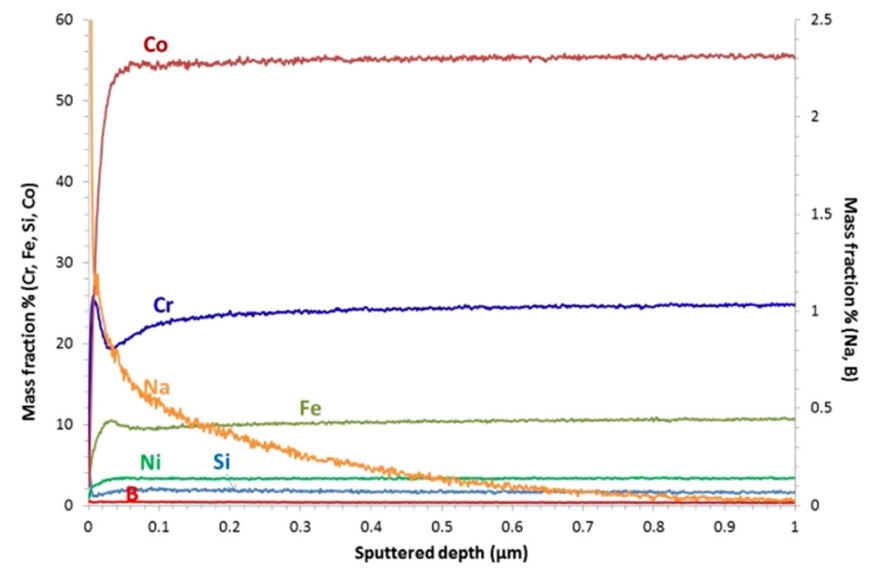

Fig. 9. Elementary profile of CoCrW alloy (PTAW) surface after exposure in $\mathrm{Na}$ at $400^{\circ} \mathrm{C}$ for $5000 \mathrm{~h}$ measured by GDOES.

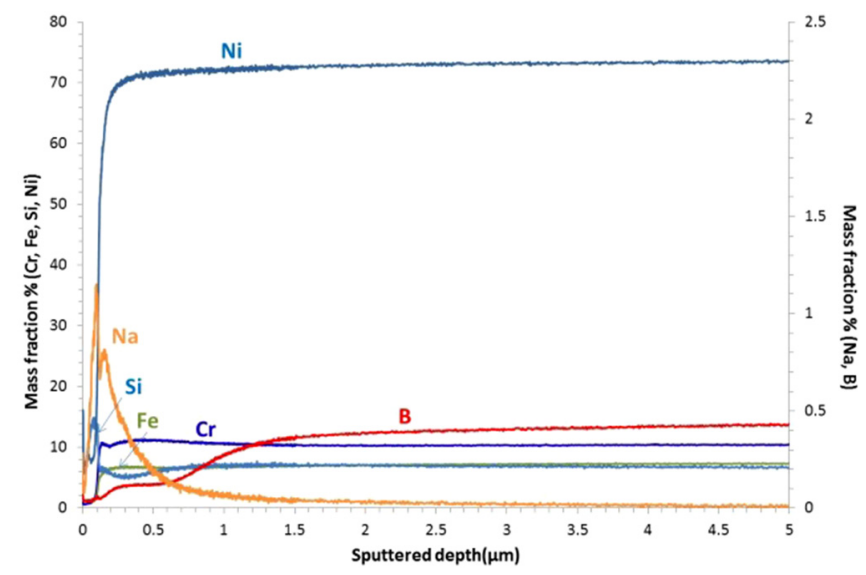

Fig. 10. Elementary profile of NiCrSiWB alloy (PTAW) surface after exposure in $\mathrm{Na}$ at $400{ }^{\circ} \mathrm{C}$ for $5000 \mathrm{~h}$ measured by GDOES.

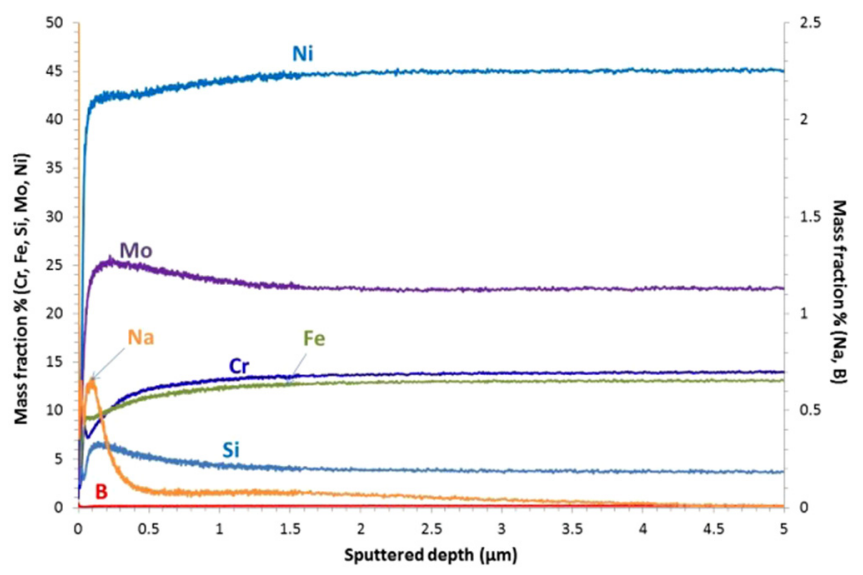

Fig. 11. Elementary profile of NiMoCrSi alloy (PTAW) surface after exposure in $\mathrm{Na}$ at $400^{\circ} \mathrm{C}$ for $5000 \mathrm{~h}$ measured by GDOES.

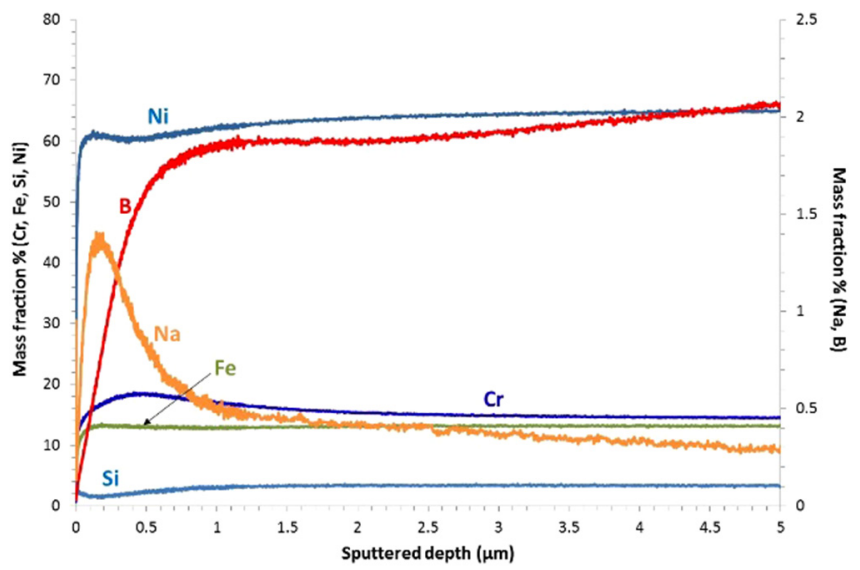

Fig. 12. Elementary profile of NiCrBSi alloy A (PTAW) surface after exposure in $\mathrm{Na}$ at $400{ }^{\circ} \mathrm{C}$ for $5000 \mathrm{~h}$ measured by GDOES.

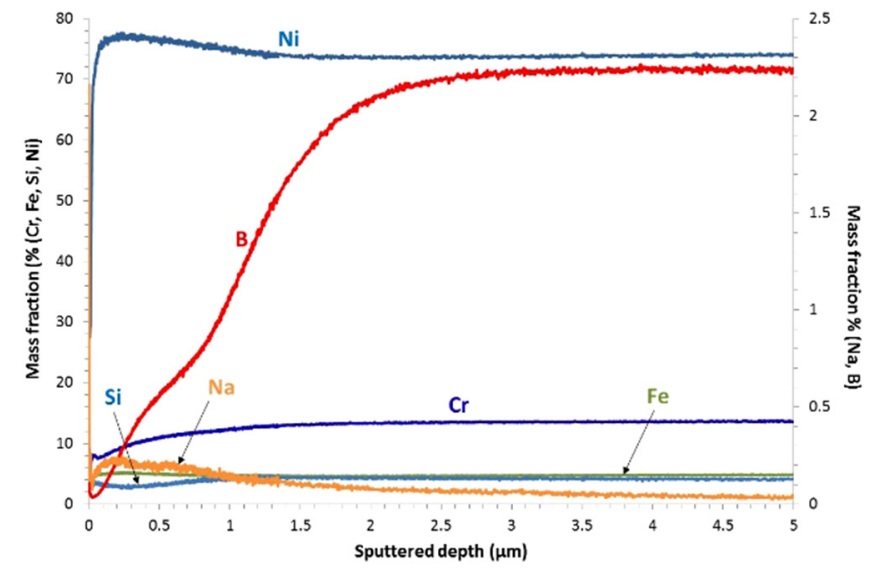

Fig. 13. Elementary profile of NiCrBSi alloy A (LC) surface after exposure in $\mathrm{Na}$ at $400^{\circ} \mathrm{C}$ for $5000 \mathrm{~h}$ measured by GDOES. 


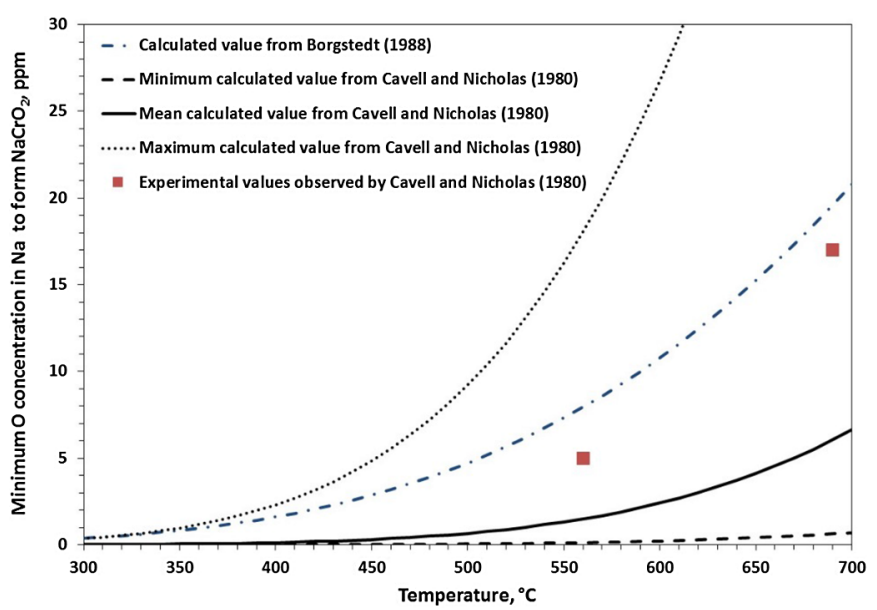

Fig. 14. Minimum oxygen concentration in sodium necessary to form $\mathrm{NaCrO}_{2}$ on $316 \mathrm{~L}$ stainless steel from literature data. For the calculated value from Borgstedt et al. [17], the activity of chromium in $316 \mathrm{~L}(\mathrm{~N})$ was taken from Azad et al. [18] and the enthalpy of formation of $\mathrm{Na}_{2} \mathrm{O}$ and $\mathrm{NaCrO}_{2}$ taken from Borgstedt et al. [17]. For all curves, the solubility law of oxygen in $\mathrm{Na}$ was taken from Noden et al. [19].

Boron dissolution in sodium has already been observed for austenitic steels at 600 and $700{ }^{\circ} \mathrm{C}$ by Borgstedt et al. [14] even if the boron solubility law in sodium as a function of temperature is not well established in the literature [15]. The order of magnitude of the apparent diffusion coefficient of boron in the boron containing coatings, $D_{\text {app }}$, was calculated by fitting the measured boron depletion profiles with the solution of the 2nd Fick's law proposed for diffusion of species in a semi-infinite media and with a constant boron concentration at the coating surface equal to zero [16]. A $D_{\text {app }}$ value around $10^{-15} \mathrm{~cm}^{2} / \mathrm{s}$ was found. From this apparent diffusion coefficient, the maximum boron depleted zone thickness was evaluated to be around $30 \mu \mathrm{m}$ after $60 \mathrm{yr}$ at $400^{\circ} \mathrm{C}$ which is quite reasonable.

Secondly, chromium was depleted in a thin zone $(<0.5 \mu \mathrm{m})$ below the surface. For CoCrW alloy, this chromium depletion zone was clearly accompanied by a chromium-enriched zone at the sodium-coating interface (Fig. 9). This combined chromium enrichment and depletion on CoCrW alloy could indicate the formation of the ternary oxide $\mathrm{NaCrO}_{2}$ on the coating surface. This ternary oxide is indeed known to be stable at low oxygen concentration in sodium. According to literature data, a minimum oxygen concentration value between 0.1 and 2 ppm is necessary to stabilize $\mathrm{NaCrO}_{2}$ on $316 \mathrm{~L}$ stainless steel (which contains about 17 wt. $\%$ of $\mathrm{Cr}$ ) at $400^{\circ} \mathrm{C}$ in $\mathrm{Na}$ (Fig. 14). This minimum oxygen concentration value to stabilize $\mathrm{NaCrO}_{2}$ should be even lower for $\mathrm{CoCrW}$ alloy since this alloy contains a higher concentration of chromium, about 28 wt.\%. Despite its likely presence, $\mathrm{NaCrO}_{2}$ could not be detected on the surface of CoCrW alloy by XRD analysis, even using grazing angle, meaning that, if formed, its amount on the surface was very low and maybe discontinuous. The chromium enrichment observed on the surface of CoCrW alloy was hardly detectable for the other alloys in good agreement with the likely lower amount of $\mathrm{NaCrO}_{2}$ formed on their surface because of the

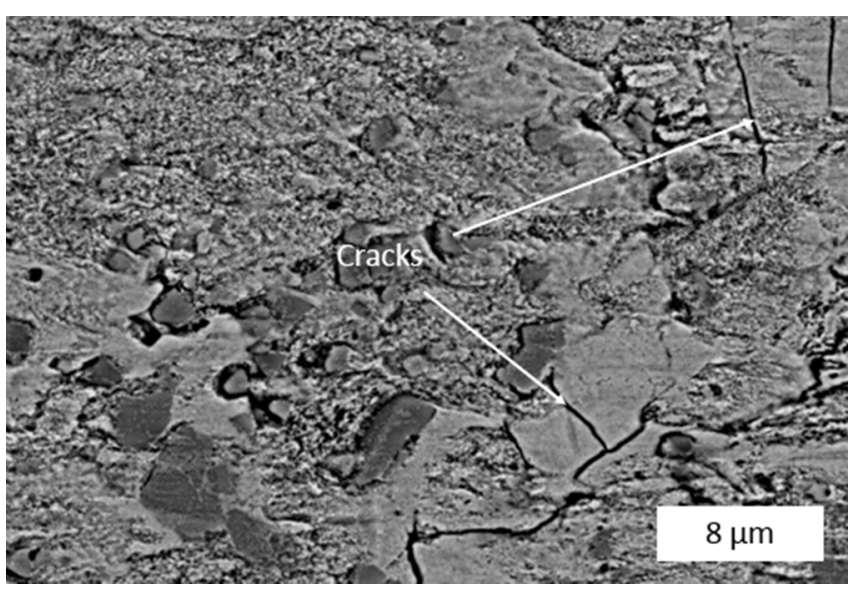

Fig. 15. Cracks formed on NiCrBSi alloy A (PTAW) surface before exposure in sodium observed by FESEM (surface).

much lower chromium concentration contained in these alloys.

Finally, for the NiCrBSi and NiCrSiWB coatings, whatever the deposition process, the concentration of silicon was observed to slightly increase at the extreme surface and to be depleted underneath over a $0.5 \mu \mathrm{m}$-thick region. The origin of Si enrichment on the surface combined with its depletion underneath is unclear. It might reflect the formation of sodium silicate $\mathrm{NaSi}_{2} \mathrm{O}_{5}$ at the coating surface or the dissolution of $\mathrm{Si}$ in sodium followed by its redeposition on the coating surface during the cooling of the sample [14]. The strong reactivity of silicon in hot sodium is quite known in literature. In particular, silicon and their oxides are soluble in sodium. The solubility of Si in sodium was estimated by interpolation around 100 molar ppm at $400{ }^{\circ} \mathrm{C}[14]$. In consequence, its presence in the coating alloy should be detrimental for its corrosion behaviour. Nevertheless, it appeared that, at $400^{\circ} \mathrm{C}$, its influence on the degradation kinetics of the $\mathrm{Si}$ containing coatings was very low. The enrichment and depletion of silicon was not observed for NiMoCrSi alloy and CoCrW alloy in spite of the fact that they contained 3-4 wt. $\%$ and $1 \mathrm{wt} . \%$ of $\mathrm{Si}$, respectively. This observation reveals that the reactivity of silicon depends on the microstructure and phase composition of the alloy. In particular, it could be proposed that Si dissolved in the nickel matrix, as it is the case for NiCrBSi and NiCrSiWB alloys, is more reactive (soluble) than Si contained in Laves phases as in NiMoCrSi alloy. Both boron and silicon dissolution in sodium participate to the mass loss of the coatings observed in Figure 6. For all coatings, the region where silicon and boron were depleted (depth $<1 \mu \mathrm{m})$ contained a high concentration of sodium $(>5 \%$ mass) and micrometer-sized voids (Fig. 7$)$. Sodium diffused even deeper in the NiCrBSi type coatings (about $15 \mu \mathrm{m})$. The penetration depth of sodium and its concentration were believed to be strongly linked to the density and depth of cracks and porosity formed on the coating surface during the process. This scenario is in good agreement with the highest density of cracks observed on the surface of the NiCrBSi type coating (Figs. 15 and 16). The sodium penetration depth was only around $2 \mu \mathrm{m}$ for $\mathrm{CoCrW}$ alloy in good agreement with the absence of visible 


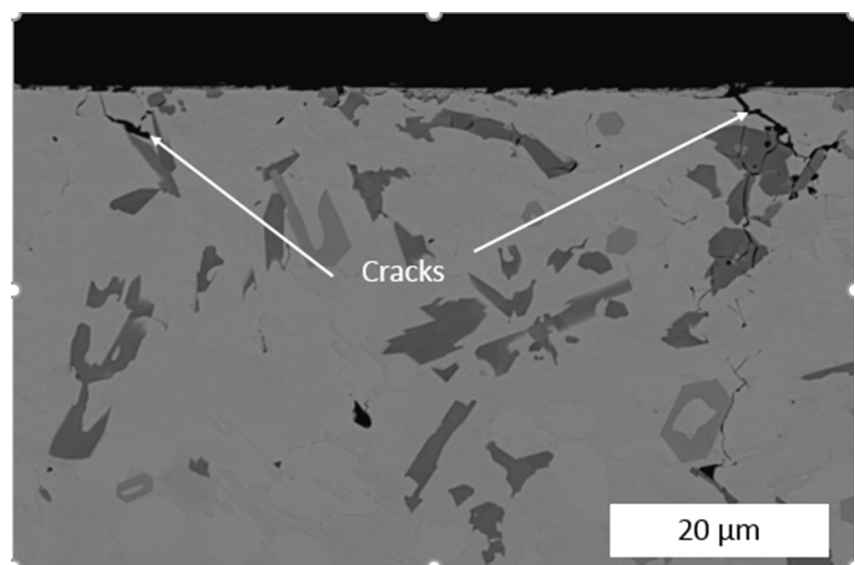

Fig. 16. Cracks formed on NiCrBSi alloy A (PTAW) surface before exposure in sodium observed by FESEM (cross section).

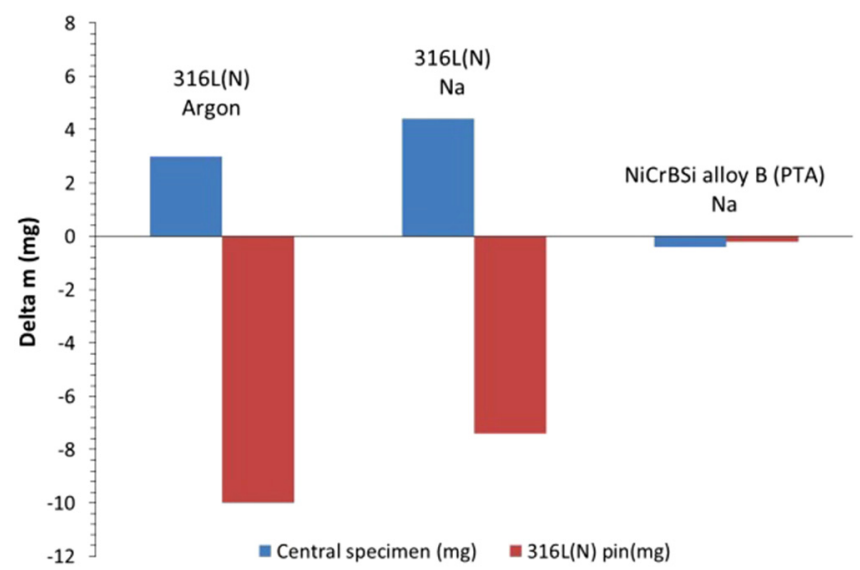

Fig. 17. Mass evolution of pin and central specimens for $316 \mathrm{~L}$ $(\mathrm{N})-316 \mathrm{~L}(\mathrm{~N})$ friction test in argon and sodium and for $316 \mathrm{~L}(\mathrm{~N})-$ $\mathrm{NiCrBSi}$ alloy B (PTAW) friction test in sodium at $200{ }^{\circ} \mathrm{C}$ under $31 \mathrm{MPa}$

cracks on its surface. The higher weight gain observed for NiMoCrSi deposited by LC could also be explained as well by a higher penetration of sodium at the surface combined to a low dissolution rate. The influence of sodium penetration on the tribological properties in sodium is unknown and needs to be investigated. The deposition process had no impact on the corrosion kinetics of CoCrW alloy but affected that of NiCrBSi alloy A. The boron depletion was larger for NiCrBSi alloy A deposited by LC (Fig. 13) than deposited by PTAW (Fig. 12) in good agreement with its larger mass loss shown in Figure 6.

In conclusion, all tested hardfacing alloys showed relatively good compatibility in purified sodium at $400{ }^{\circ} \mathrm{C}$ up to $5000 \mathrm{~h}$ of exposure. This observation confirmed literature data indicating corrosion rates from $0.02 \mu \mathrm{m}$ to $0.1 \mu \mathrm{m} / \mathrm{yr}$ for these alloy grades in flowing sodium at $400{ }^{\circ} \mathrm{C}$ [20]. If corrosion ranking has to be done, the best corrosion behaviour in sodium was observed for CoCrW alloy and NiMoCrSi alloys and the less corrosion resistant was for the NiCrBSi-type alloys in agreement, again, with literature

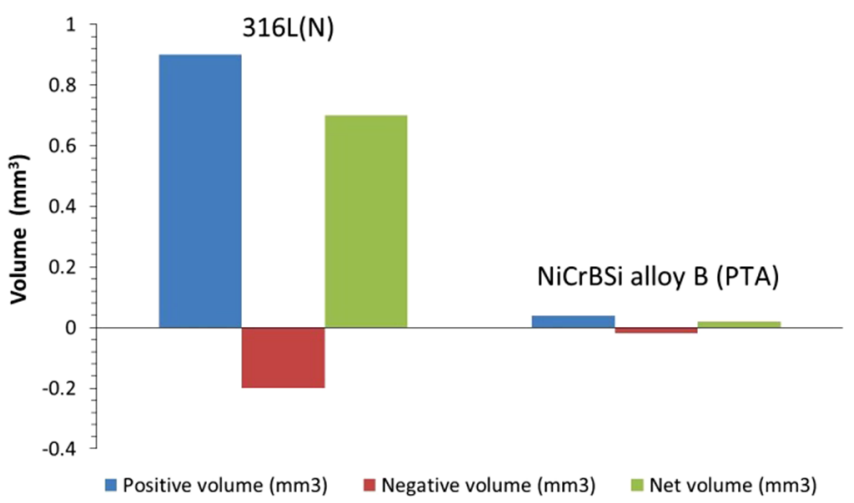

Fig. 18. Positive and negative volumes measured by $3 \mathrm{D}$ microscopy on the worn surface of the central specimen after friction test in sodium.

[21]. The lower corrosion resistance of NiCrBSi coatings is likely due to the presence of large amounts of boron and silicon in solid solution, two elements which are highly soluble in sodium.

\section{Tribological behaviour in sodium}

A comparison of the mass evolution of the specimens after friction tests of $316 \mathrm{~L}(\mathrm{~N})$ against itself and $316 \mathrm{~L}(\mathrm{~N})$ against $\mathrm{NiCrBSi}$ alloy B (PTAW) in purified sodium at $200^{\circ} \mathrm{C}$ is shown in Figure 17. The wear resistance of both specimens (central specimen and outer pins) was higher when 316L (N) was rubbed against hardfacing NiCrBSi alloy. Very low mass transfer occurred during the $316 \mathrm{~L}(\mathrm{~N})-\mathrm{NiCrBSi}$ friction test which contrasted with the $316 \mathrm{~L}(\mathrm{~N})-316 \mathrm{~L}(\mathrm{~N})$ friction test where steel was massively transferred from the outer pins to the central one (Fig. 17). This massive adhesive wear of $316 \mathrm{~L}(\mathrm{~N})-316 \mathrm{~L}(\mathrm{~N})$ contact was also observed when the friction test was carried out under inert gas indicating, thus, that this behaviour was not sodium dependent. The lower adhesive wear observed during the friction of $316 \mathrm{~L}(\mathrm{~N})$ on $\mathrm{NiCrBSi}$ alloy could be explained by the higher hardness of $\mathrm{NiCrBSi}$ alloy $(585 \pm 15$ Hv1) than $316 \mathrm{~L}(\mathrm{~N})(200 \pm 15 \mathrm{Hv} 1)$ (Fig. 18). In contrast, the friction coefficient measured during the 316L(N)-NiCrBSi alloy B friction test was higher than the one measured for the $316 \mathrm{~L}(\mathrm{~N})-316 \mathrm{~L}(\mathrm{~N})$ friction test (Fig. 19). No effect of the environment, purified $\mathrm{Na}$ or Argon, could be observed on the friction coefficient values measured for $316 \mathrm{~L}(\mathrm{~N})-316 \mathrm{~L}(\mathrm{~N})$ friction test (Fig. 19). This result was in good agreement with the fact that, in both environments, no lubricating oxide layer was formed on the steel surface.

As it can be observed in Figure 20, the oxygen concentration in sodium had an important effect on the tribological behaviour of the two specimens in contact and, more specifically, on the friction coefficient. The friction coefficient of $316 \mathrm{~L}(\mathrm{~N})$ against $\mathrm{NiCrBSi}$ alloy B (PTAW) was lowered by a factor of 1.5 by increasing the oxygen concentration in sodium from levels below 1 ppm (purified $\mathrm{Na}$ ) to levels over $10 \mathrm{ppm}$ (non-purified $\mathrm{Na}$ ). This effect had already been observed in past studies and was mainly 


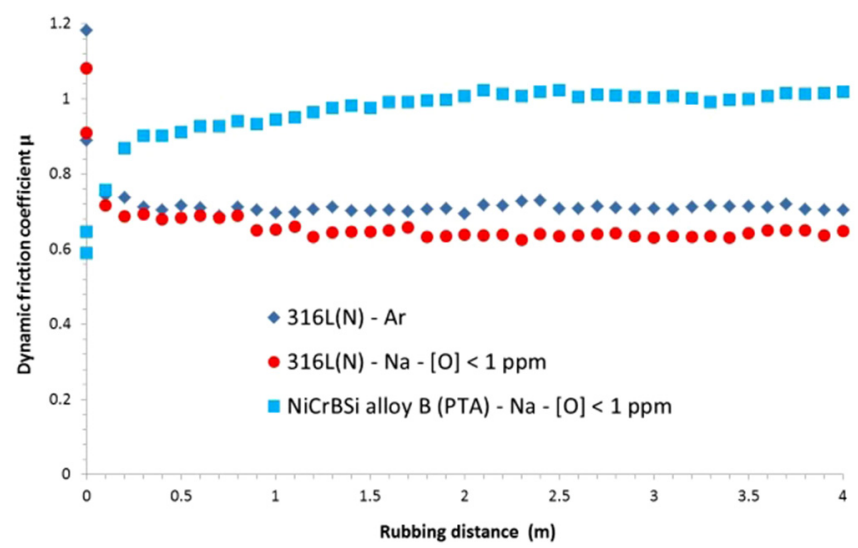

Fig. 19. Dynamic friction coefficient of $316 \mathrm{~L}(\mathrm{~N})-316 \mathrm{~L}(\mathrm{~N})$ and $316 \mathrm{~L}(\mathrm{~N})-\mathrm{NiCrBSi}$ alloy $\mathrm{B}(\mathrm{PTAW})$ contact in purified sodium $([\mathrm{O}]<1 \mathrm{ppm})$ or argon at $200{ }^{\circ} \mathrm{C}$ under $31 \mathrm{MPa}$ at $1 \mathrm{~mm} / \mathrm{s}$.

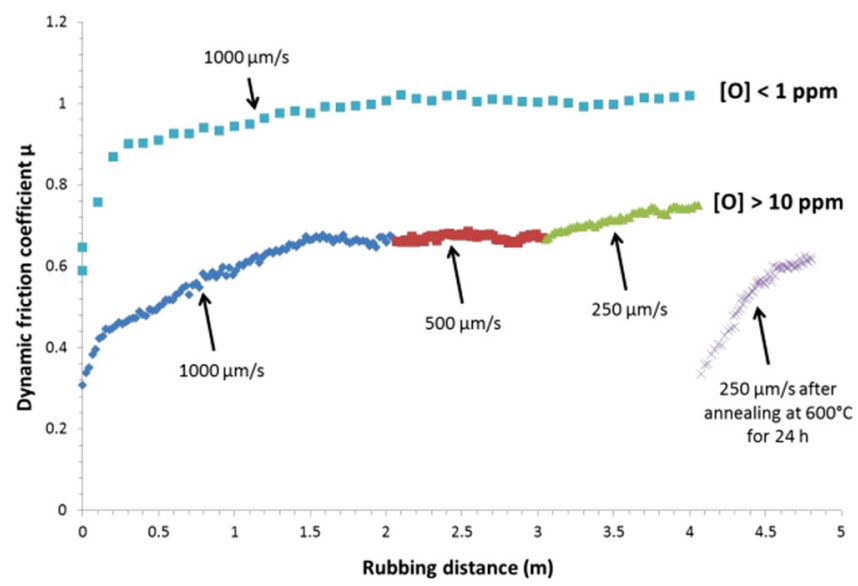

Fig. 20. Dynamic friction coefficient of $316 \mathrm{~L}(\mathrm{~N})-\mathrm{NiCrBSi}$ alloy $\mathrm{B}$ (PTAW) contact in purified $([\mathrm{O}]<1 \mathrm{ppm})$ and non-purified sodium $([\mathrm{O}]>10 \mathrm{ppm})$ at $200^{\circ} \mathrm{C}$ under $31 \mathrm{MPa}$.

attributed to the formation of lubricating oxide such as chromite $\left(\mathrm{NaCrO}_{2}\right)$ on the surface of the steels [2,5,22]. This proposed beneficial effect of surface oxide layer on the samples was evaluated by carrying out a complementary friction test at $200^{\circ} \mathrm{C}$ after annealing the specimens in nonpurified sodium $([\mathrm{O}]>10 \mathrm{ppm})$ at $600^{\circ} \mathrm{C}$ for $24 \mathrm{~h}$. The friction coefficient decreased drastically to a value close to 0.3 then increased progressively with rubbing distance to its initial value, around 0.7. This time evolution of the friction coefficient was in good agreement with the formation of a lubricating oxide layer after exposure at high temperature in non-purified sodium and its progressive removal by friction ending up with metal-metal contact friction. This assumption was confirmed by the observation of chromium-rich oxide on the surface of the $316 \mathrm{~L}(\mathrm{~N})$ pin after annealing test (Fig. 21). The exact nature of the formed oxide crystals was not identified by XRD but it was proposed that these oxide crystals were $\mathrm{NaCrO}_{2}$ owing to the fact that they were rich in chromium and their morphology was very similar to the $\mathrm{NaCrO}_{2}$ crystals identified by Cavell et al. after exposing AISI 316

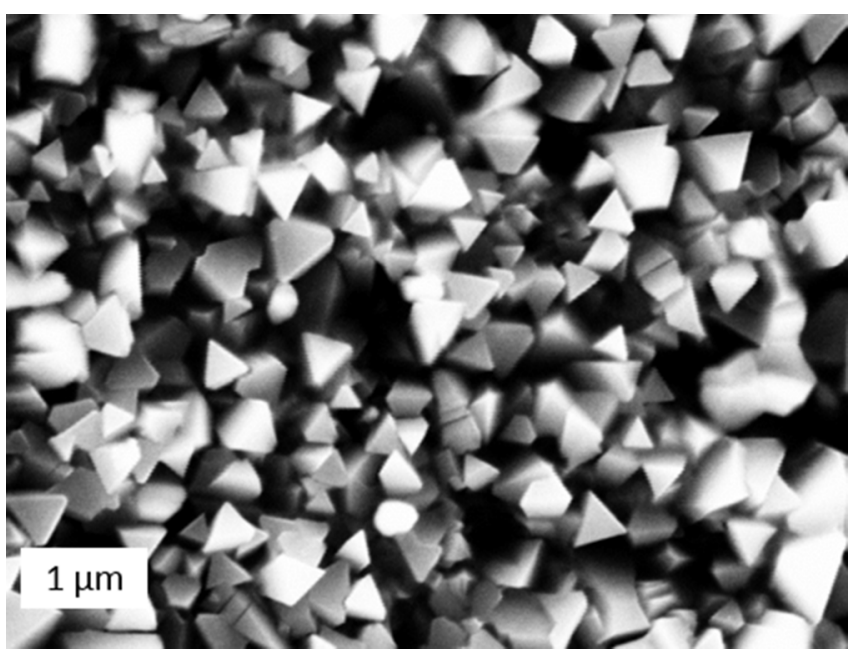

Fig. 21. FESEM image (secondary electron contrast) of the oxide crystals formed on the $316 \mathrm{~L}(\mathrm{~N})$ pin surface after annealing in oxygen-containing sodium at $600^{\circ} \mathrm{C}$ for $24 \mathrm{~h}$ (Fig. 13).

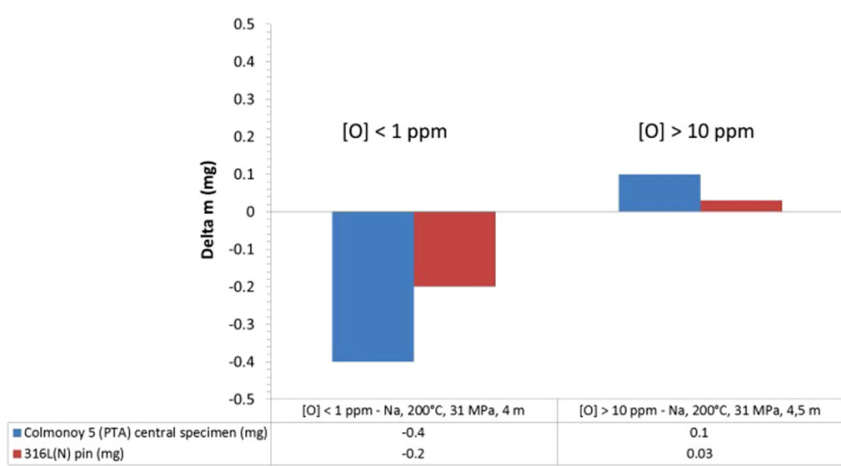

Fig. 22. Mass evolution of pin (red) and central specimens (blue) for $316 \mathrm{~L}(\mathrm{~N})-\mathrm{NiCrBSi}$ alloy $\mathrm{B}(\mathrm{PTAW})$ friction test in purified and non-purified sodium at $200^{\circ} \mathrm{C}$ under $31 \mathrm{MPa}$.

stainless steel in static sodium containing 1-24 wppm of oxygen at $450-675^{\circ} \mathrm{C}[23]$.

The formation of chromite at $600^{\circ} \mathrm{C}$ in sodium containing more than $10 \mathrm{wpm}$ of oxygen was in good agreement with the minimum oxygen concentration proposed in literature for its formation, about $10 \mathrm{wpm}$ at $600{ }^{\circ} \mathrm{C}$ (Fig. 14). Two scenarios have been proposed in literature to explain the beneficial effects of chromite on the friction coefficient. On one hand, Nicholas and Cavell [22] have proposed that the mechanism involved in chromite lubrication is the deposition on the surface of oriented crystals which shear and form a low shear-strength oriented layer somewhat like that usually proposed in graphite lubrication. On the other hand, Radcliffe considered this last mechanism unnecessarily complex and has proposed that chromite simply acts by reducing adhesion and junction growth during rubbing [5].

Finally, it was observed that the wear resistance of the rubbing contact was also slightly improved with the oxygen concentration in sodium (Fig. 22). More friction tests are needed to confirm this tendency. 


\section{Conclusions}

Several nickel-base alloys were evaluated as candidates for hardfacing alloys in SFRs. All of them showed good chemical compatibility in sodium at $400{ }^{\circ} \mathrm{C}$ for at least $5000 \mathrm{~h}$, whatever the deposition process (Plasma Transferred Arc Welding or Laser Cladding). In-sodium friction tests revealed better wear behaviour for $316 \mathrm{~L}(\mathrm{~N})-$ NiCrBSi alloy contact than for $316 \mathrm{~L}(\mathrm{~N})-316 \mathrm{~L}(\mathrm{~N})$ contact. However, the measured friction coefficient was slightly higher. The beneficial influence of increasing the oxygen concentration in sodium on the friction coefficient, already demonstrated in literature, has been confirmed. Friction tests with all the hardfacing nickel base alloy candidates are needed at various stress contacts, sliding velocities and temperature for identifying the best alternative to Stellite $6^{\circledR}$ in SFRs.

This project was supported and funded by CEA, FRAMATOME and EDF within the ASTRID project.

\section{Author contribution statement}

F. Rouillard has written the article and has leaded the experimental campaign. B. Duprey has carried out the experiments in sodium. M. Tabarant has made the GDOES analyses. P. Aubry and C. Blanc have provided the coatings deposited by laser and made their metallurgical characterization. The other co-authors have contributed to this work by providing support, proofreading and expert viewpoints on the different topics discussed in the article.

\section{References}

1. E. Wild, K.J. Mack, M. Gegenheimer, Liquid Metal Tribology in Fast Breeder Reactors (Kernforschungszentrum, Karlsruhe, 1984)

2. R.N. Johnson, R.C. Aungst, N.J. Hoffman, M.G. Cowgill, G.G. Whitlow, W.L. Wilson, Development of low friction materials for LMFBR components, in M.H. Cooper (Ed.), Proceeding in First International Conference on Liquid Metal Technology in Energy Production, 1976, Champion, p. 122

3. E. Wild, K.J. Mack, Friction and wear in liquid-metal systems: compatibility problems of test results obtained from different test facilities, in M.H. Cooper (Ed.), Proceeding in First International Conference on Liquid Metal Technology in Energy Production, 1976, Champion, p. 131

4. G.A. Whitlow, W.L. Wilson, T.A. Galioto, R.L. Miller, S.L. Schrock, N.J. Hoffman, J.J. Droher. R.N. Johnson, Corrosion and tribological investigations of chromium carbide coatings for sodium cooled reactor applications, in M.H. Cooper (Ed.),
Proceeding in First International Conference on Liquid Metal Technology in Energy Production, 1976, Champion, p. 138

5. S.J. Radcliffe, Friction coefficient of AISI 316 stainless steel in impure and in zirconium hot-trapped sodium, in: D. Dowson (Ed.), Proceeding of the 7th Leeds-Lyon Symposium on Tribology, Institute of Tribology, p. 64

6. H. Borgstedt, C.K. Mathews, Applied Chemistry of the Alkali Metals (Kluwer Academic/Plenum Publishers, Dordrecht, 1987)

7. J. Guidez, B. Bonin, Réacteurs nucléaires à caloporteur sodium (2014)

8. J-L. Courouau, F. Balbaud-Célérier, V. Lorentz, T. Dufrenoy, Corrosion by liquid sodium of materials for sodium fast reactors: the CORRONa testing device, in Proceeding in International Congress on Advances in Nuclear Power Plants (ICAPP '11), Nice, France, 2011, p. 2

9. J. Guidez, Phénix: The experience feedback (EDP Sciences, Paris, 2013)

10. G. Rolland, C. Cossange, A. Andrieu, M. Blat-Yrieix, P. Sallamand, M. Duband, C. Blanc, P. Aubry, F. Rouillard, T. Marlaud, Coating toughness estimation through a Laser Shock Testing in Ni-Cr-B-Si-C Coatings, Mater. Sci. Forum 941, 1886 (2018)

11. H. Kumar, V. Ramakrishnan, S.K. Albert, C. Meikandamurthy, B.V.R. Tata, A.K. Bhaduri, High Temperature wear and friction behaviour of $15 \mathrm{Cr}-15 \mathrm{Ni}-2 \mathrm{Mo}$ titanium-modified austenitic stainless steel in liquid sodium, Wear 270, 1 (2010)

12. A.K. Badhuri, R. Indira, S.K. Albert, B.P.S. Rao, S.C. Jain, S. Asokkumar, Selection of hardfacing material for component of the Indian Prototype Fast Breeder Reactor, J. Nucl. Mater. 334, 109 (2004)

13. H.U. Borgstedt, G. Frees, G. Drechsler, Korrosions reaktionen sauerstoffempfindlicher Metalle in flüssigem Natrium mit Oxidgehalten. I. Reaktionen von Zirkonium und Zircaloy2, Werstoffe und Korrosion 21, 568 (1970)

14. H.U. Borgstedt, G. Frees, H. Schneider, Corrosion and creep of pressurized stainless-steel tubes in liquid-sodium at 873 and 973 K, Nucl. Technol. 34, 290 (1977)

15. H.U. Borgstedt, C. Guminski, IUPAC-NIST Solubility Data Series. 75. Nonmetals in Liquid Alkali Metals, J. Phys. Chem. Ref. Data 30, 835 (2001)

16. J. Crank, The Mathematics of Diffusion, 2nd edn. (Oxford Science Publications, Oxford, 1975)

17. N.P. Bhat, H.U. Borgstedt, Corrosion behaviour of structural materials in sodium influenced by formation of ternary oxides, Werkstoffe und Korrosion 39, 115 (1988)

18. A.M. Azad, O.M. Sreedharan, J.B. Gnanamoorthy, A novel determination of thermodynamic activities of metals in an AISI 316 stainless steel by a metastable emf method, J. Nucl. Mater. 144, 94 (1987)

19. J.D. Noden, A general equation for the solubility of oxygen in liquid sodium, J. Br. Nucl. Energy Soc. 12, 57 (1973) [Addendum J. Br. Nucl. Energy Soc. 12, 329 (1973)]

20. E. Yoshida, Y. Hirakawa, S. Kano, I. Nihei, In-sodium tribological study of cobalt-free hard facing materials for contact and sliding parts of FBR components, in SFEN, 
Proceeding in the Fourth International Conference on Liquid Metal Engineering and Technology, Avignon, 1998, paper 502

21. S. Kano et al., Investigation of tribological phenomena in sodium for LMFBR, in J.M. Dahlke (Ed.), Proceeding in the Second International Conference on Liquid Metal and Technology in Energy Production, Richland 1980, paper $3-60$
22. M.G. Nicholas, I.W. Cavell, The formation of chromite on AISI 316 and other chromium containing alloys, in J.M. Dahlke (Ed.), Proceeding in the Second International Conference on Liquid Metal Technology in Energy Production, Richland, 1980, paper 3-35

23. I.W. Cavell, M.G. Nicholas, Some observations concerned with the formation of chromite on AISI 316 exposed to oxygenated sodium, J. Nucl. Mater. 95, 129 (1980)

Cite this article as: Fabien Rouillard, Brigitte Duprey, Jean-Louis Courouau, Raphaël Robin, Pascal Aubry, Cécile Blanc, Michel Tabarant, Hicham Maskrot, Laetitia Nicolas, Martine Blat-Yrieix, Gilles Rolland, Thorsten Marlaud, Evaluation of cobalt free coatings as hardfacing material candidates in sodium-cooled fast reactor and effect of oxygen in sodium on the tribological behaviour, EPJ Nuclear Sci. Technol. 5, 10 (2019) 